p-ISSN 1907-9850

e-ISSN 2599-2740

\title{
KARAKTERISASI BATU KAPUR ALAM BUKIT JIMBARAN BALI
}

\author{
Y. Ulfa, *A. A. B. Putra, dan I N. Simpen \\ Program Studi Kimia Fakultas Matematika dan Ilmu Pengetahuan Alam Universitas Udayana \\ Jalan Kampus Unud-Jimbaran, Jimbaran-Bali, Indonesia \\ "Email: bawa_putra@unud.ac.id
}

\begin{abstract}
ABSTRAK
Penelitian ini mengenai karakterisasi batu kapur alam daerah Bukit Jimbaran, Bali. Penelitian ini bertujuan untuk mempelajari komposisi kimia dan morfologi mikro batu kapur Bukit Jimbaran.Penelitian dilakukan dalam tahapan berikut, yaitu batu kapur digerus sampai halus, selanjutnya diayak dengan ayakan ukuran 0,25-0,50 mm. Batu kapur yang telah halus dipanaskan menggunakan oven pada suhu $100^{\circ} \mathrm{C}$ selama 24 jam, kemudian dilanjutkan dengan analisis menggunakan FTIR, XRD dan SEM. Spektra FTIR menggambarkan secara dominan adanya gugus fungsi O-H, C-H, dan $\mathrm{C}-\mathrm{O}$ dan di dalamnya memiliki komposisi $\mathrm{CaCO}_{3}$ dan $\mathrm{CaO}$. Batu kapur Bukit Jimbaran hasil pengukuran kristal $\mathrm{CaO}$ dengan menggunakan persamaan Scherrer adalah 51,39 nm. Pengamatan menggunakan SEM menunjukkan morfologi mikro berbentuk bunga (vaterit).
\end{abstract}

Kata kunci: batu kapur, Scherrer, $\mathrm{CaCO}_{3}, \mathrm{CaO}$, vaterit

\begin{abstract}
This research is about the characterization of naturar limestone in the Bukit Jimbaran area of Bali. The aim of this research was to learn chemical composition and micromorphology of Bukit Jimbaran limestone. The research was conducted in sequential steps as described below i.e. the limestone was grinded and sieved in size of 0.25-0.50 $\mathrm{mm}$. Fine limestone, then was heated by using oven at $100^{\circ} \mathrm{C}$ for 24 hours and analyzed by FTIR, XRD and SEM.

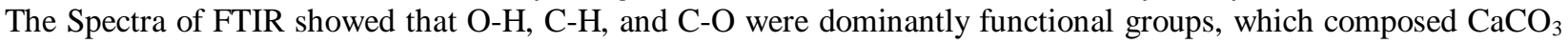
and $\mathrm{CaO}$. The results of $\mathrm{CaO}$ crystal measurements using Scherrer equation is 51,39 $\mathrm{nm}$. Micromorphology observation by using SEM showed size shaped (vaterite) of Bukit Jimbaran limestone.
\end{abstract}

Keywords: Limestone, Scherrer, $\mathrm{CaCO}_{3}, \mathrm{CaO}$, vaterite

\section{PENDAHULUAN}

Batu kapur merupakan salah satu mineral yang sangat melimpah di Indonesia dan merupakan salah satu bahan utama dalam pembuatan keramik, bahan perekat dalam industri, dan bahan baku semen.

Batu kapur adalah batuan padat yang mengandung banyak kalsium karbonat (Lukman, et al., 2012) yang merupakan material metastabil karena dalam waktu tertentu dapat berubah menjadi kalsit (Sucipto, et.al., 2007).

Mineral yang terkandung dalam batu kapur sebagian besar mineral kalsium karbonat $\left(\mathrm{CaCO}_{3}\right)$ yaitu sekitar 95\%, dimana kandungan kalsium karbonat ini dapat diubah menjadi kalsium oksida dengan kalsinasi, sehingga lebih mudah dimurnikan untuk mendapatkan kalsiumnya dan hasil pemurnian ini dapat dimanfaatkan dalam bidang kesehatan, yakni dalam aplikasi klinis untuk penelitian dibidang medis dan perkembangan dalam pembuatan biomaterial sehingga mendapatkan nilai ekonomis (Gusti, 2008).

Noviyanti, et al. (2015) melakukan penelitian karakterisasi kalsium karbonat $\left(\mathrm{CaCO}_{3}\right)$ dari batu kapur Kelurahan Tellu, berlokasi di Kelurahan Tellu Limpoe Kecamatan Suppa dengan metode kalsinasi selama 4 jam pada variasi suhu 550,650 , dan $750^{\circ} \mathrm{C}$. Hasil penelitian menyatakan bahwa semakin tinggi suhu, kadar kalsit semakin rendah dan fasa yang terbentuk semakin banyak. Hal ini terbukti dari karakterisasi $\mathrm{CaCO}_{3}$ hasil kalsinasi menggunakan XRD (X-Ray Difraction) menunjukkan fasa kalsit yang diperoleh untuk masing-masing suhu yaitu 98,8; 92,2 ; dan $84,0 \%$, dimana juga terbentuk $\mathrm{CaO}$ 
pada suhu kalsinasi $\quad 750^{\circ} \mathrm{C}$ akibat batu kapur mengalami dekomposisi karena adanya energi panas. Berdasarkan analisis SEM (Scanning Electron Microscopy), morfologi $\mathrm{CaCO}_{3}$ diperoleh menyerupai kubus namun ukuran partikelnya tidak merata dan tidak beraturan disebabkan adanya faktor pengotor. Sedangkan untuk hasil analisis EDS (Dispersive X-Ray Spectroscopy) diperoleh kandungan kalsium yang terdapat dalam batu kapur cukup tinggi karena unsur pengotor kurang dari $15 \%$.

Daerah Bukit Jimbaran, Kuta Selatan, Badung, Bali merupakan daerah yang sangat kaya akan batu kapur, bisa dikatakan seluruh daerah tersusun atas kapur. Namun belum ada penelitian mengenai kualitas kapur di daerah ini. Bukit ini tersusun atas batu kapur yang sangat melimpah, dan sangat dekat dengan wilayah pantai. Bukit ini terletak di bagian selatan pulau Bali yang mana terjadi pengendapan oleh batu gamping yang kemudian membentuk daerah Bukit Jimbaran (formasi Selatan), sehingga wilayah ini memiliki kondisi geologi yang sangat berbeda dengan wilayah dataran lainnya. Untuk itu perlu dilakukan penelitian terhadap batu kapur daerah Bukit Jimbaran agar kekayaan alam di daerah dapat dimanfaatkan dengan baik dan maksimal.

\section{MATERI DAN METODE}

\section{Bahan}

Bahan yang digunakan dalam penelitian ini adalah aquades dan serbuk batu kapur daerah Bukit Jimbaran, Kuta Selatan, Badung, Bali.

\section{Peralatan}

Alatxyangxdigunakan dalamxpenelitian ini antaraxlain : mortar, gelas baker, neraca analitik, ayakan ukuran 0,25-0,5 mm, kertas saring whatman nomor 42, cawan porselen, stop watch, oven, FTIR (Fourier Transform Infra Red), dan SEM (Scanning Electron Microscopy).

\section{Cara Kerja \\ Pengambilan Sampel}

Sampel yang digunakan adalah batu kapur daerah Bukit Jimbaran, sampel diambil secara manual dikawasan yang telah dipilih. Sampel diambil pada 5 tempat yang berbeda sekitar kawasan Bukit Jimbaran yang nantinya dapat mewakili seluruh batu kapur yang ada di Bukit Jimbaran. Teknik pengambilan sampel pada setiap daerah mengikuti teknik pengambilan sampel dari Neb Guide (Ferguson, et al., 2007). Selanjutnya sampel yang terkumpul digabung menjadi satu sampel.

\section{Preparasi sampel}

Sampel yang telah diambil dibawa ke Laboratorium Penelitian Program Studi Kimia Fakultas Matematika dan Ilmu Pengetahuan Alam Universitas Udayana. Setelah itu sampel digabungkan menjadi satu, lalu dicuci menggunakan aquades yang bertujuan untuk menghilangkan pengotor yang ada pada sampel lalu dikeringkan. Kemudian sampel digerus dengan mortar sampai halus, selanjutnya diayak dengan ayakan ukuran 0,25-0,50 mm, sehingga diperoleh serbuk halus yang berukuran antara 0,25-0,50 $\mathrm{mm}$. Setelah itu sampel dipanaskan dalam oven dengan temperatur $100^{\circ} \mathrm{C}$ selama 24 jam untuk menghilangkan kadar air pada batu kapur.

\section{Karakterisasi batu kapur}

Sebanyak 20 gram serbuk batu kapur yang telah dipreparasi dilakukan analisis menggunakan instrument FTIR (Fourier Transform Infra Red) untuk analisis gugus fungsi batu kapur dan SEM (Scanning Electron Microscopy) untuk mengetahui morfologi mikro dari batu kapur.

\section{HASIL DAN PEMBAHASAN}

Karakterisasi menggunakan spektroskopi infrared bertujuan untuk mengidentifikasi gugus fungsi yang terdapat dalam batu kapur Bukit Jimbaran. Spektra karakteristik yang dihasilkan muncul di daerah 4000-2100 $\mathrm{cm}^{-1}$ dan 1900-400 $\mathrm{cm}^{-1}$. Karakteristik puncak spektra inframerah pada serapan tersebut menunjukkan adanya gusus fungsi $\mathrm{OH}, \mathrm{CO}, \mathrm{CH}$, dan $\mathrm{CaO}$, seperti yang terdapat dalam Gambar 1. 


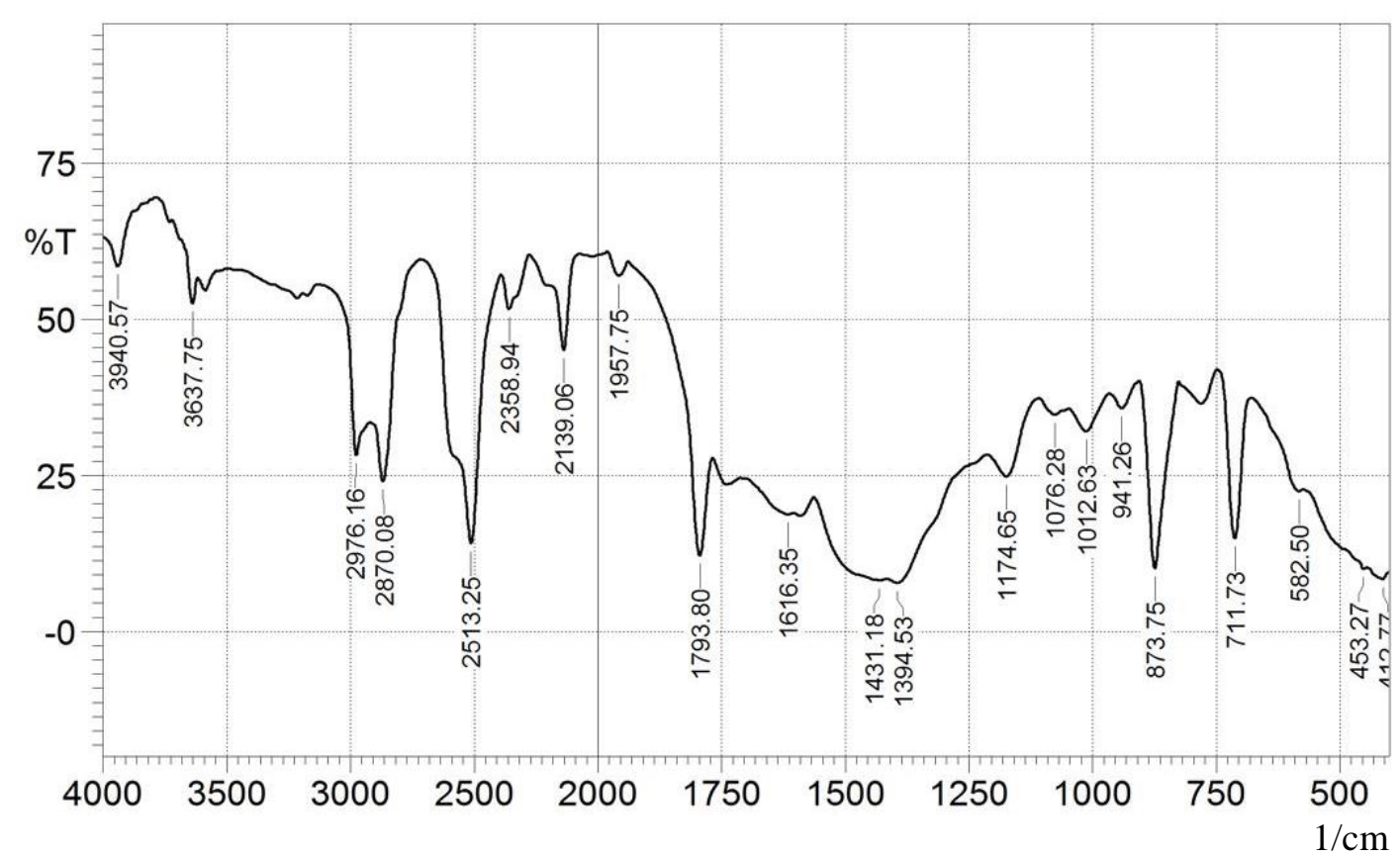

Gambar 1. Spektra FTIR batu kapur Bukit Jimbaran, Kuta Selatan, Badung, Bali

Tabel 1. Bilangan gelombag $\left(\mathrm{cm}^{-1}\right)$ karakteristik puncak gugus fungsi batu kapur Alam Bukit Jimbaran, Bali

\begin{tabular}{cccc}
\hline Nama Sampel & \multicolumn{3}{c}{ Bilangan gelombang $\left(\mathrm{cm}^{-1}\right)$ karakteristik puncak gugus fungsi } \\
\cline { 2 - 4 } & $\mathrm{OH}$ & $\mathrm{CH}$ & $\mathrm{CO}$ \\
\hline Batu kapur alam Bukit & 3637,75 & 2358,94 & 711,73 \\
Jimbaran, Bali & 3940,57 & 2513,25 & 873,75 \\
& & 2870,08 & 941,26 \\
& & 2976,16 & 1012,63 \\
& & 1076,28 \\
& & 1174,65 \\
& & 1394,53 \\
& & 1431,18 \\
& & 1616,35 \\
& & 1793,80 \\
& & & 1957,75 \\
\hline
\end{tabular}

Berdasarkan Gambar 1, maka dapat diketahui puncak-puncak pada spektra IR yang terdapat pada batu kapur Buki Jimbaran yang menunjukkan daerah gugus fungsi yang dijabarkan pada Tabel 1.

Berdasarkan Tabel 1 dapat diketahui adanya gugus $\mathrm{OH}$ bonding dengan bentuk puncak yang lebar pada batu kapur di daerah $3637,75 \mathrm{~cm}^{-1}$ dan 3940,57 $\mathrm{cm}^{-1}$. Hal ini sesuai dengan penelitian Granados, et al. (2007) menyatakan bahwa gugus $\mathrm{OH}$ dari $\mathrm{Ca}(\mathrm{OH})_{2}$ tampak pada 3647 $\mathrm{cm}^{-1}$, dan $\mathrm{OH}$ bending sebagai absorbsi molekul air pada permukaan padatan muncul pada $1647 \mathrm{~cm}^{-1}$. Penelitian Liu, et al. (2008) menyatakan bahwa spektra inframerah $\mathrm{Ca}(\mathrm{OH})_{2}$ ditunjukan dari gugus $\mathrm{OH}$ yang muncul pada daerah serapan 4000-3600 $\mathrm{cm}^{-1}$.

Daerah pada bilangan gelombang 2358,94 $\mathrm{cm}^{-1}, 2513,25 \mathrm{~cm}^{-1}, 2513,25 \mathrm{~cm}^{-1}, 2870,08 \mathrm{~cm}^{-1}$, dan $2976,16 \mathrm{~cm}^{-1}$ pada spektra IR batu kapur merupakan karakteristik puncak gugus CH. Menurut Tang, et al. (2011) sampel yang 
mengandung $\mathrm{CaO}$ tampak dalam stretching $\mathrm{CH}$ $\left(3000-2800 \mathrm{~cm}^{-1}\right)$.

Bilangan gelombang $711,73 \mathrm{~cm}^{-1}, 873,75$ $\mathrm{cm}^{-1}, 941,26 \mathrm{~cm}^{-1}, 1012,63 \mathrm{~cm}^{-1}, 1076,28 \mathrm{~cm}^{-1}$, $1174,65 \quad \mathrm{~cm}^{-1}, 1394,53 \mathrm{~cm}^{-1}, 1431,18 \mathrm{~cm}^{-}$ 1, $1616,35 \mathrm{~cm}^{-1}, 1793,80 \mathrm{~cm}^{-1}$, dan $1957,75 \mathrm{~cm}^{-1}$ merupakan daerah karekteristik gugus fungsi $\mathrm{CO}$ (Karbonil). Hasil penelitian serupa juga diperoleh Tang, et al. (2011) bahwa karakteristik absorbsi CO antara 2000-1500 $\mathrm{cm}^{-1}$ menunjukkan keberadaan kalsium karbonat dalam katalis. Pada penelitian Albuquerque, et al. (2009), pita absorbsi 1600-1400 $\mathrm{cm}^{-1}$ merupakan gugus fungsi karbonat. Dalam penelitian Alba, et al. (2010), bending karbonat terjadi pada daerah $1420 \mathrm{~cm}^{-1}$ dan $875 \mathrm{~cm}^{-1}$.

Analisis kestabilan thermal batu kapur dilakukan dengan Thermo Gravimetry Analysis (TGA), selain bertujuan untuk analisis kestabilan thermal, TGA juga digunakan untuk mengetahui kandungan pengisi material. Hal ini dapat dilihat dari Thermo Gravimetry Analysis (TGA) pada Gambar 2.

Berdasarkan Gambar 2 dapat dilihat proses pengurangan berat batu kapur dari suhu $0^{\circ} \mathrm{C}$ sampai $900^{\circ} \mathrm{C}$. Berdasarkan gambar di atas dapat diketahui bahwa semakin tinggi pemanasan terhadap material batu kapur semakin mengalami pengurangan berat, hal ini menandakan bahwa pada batu kapur sudah semakin banyak nano partikel yang telah terbentuk. Pada suhu $600^{\circ} \mathrm{C}$ terlihat pengurangan berat batu kapur sekitar $28 \%$ dari berat awal. Hal ini menunjukan sudah semakin banyak unsur penyusun yang hilang dari sampel batu kapur yang telah dikalsinasi. Pada penelitian Eva (2015) bahwa semakin meningkatnya komposisi penambahan abu sekam padi pada suhu dekomposisi $600^{\circ} \mathrm{C}$ perubahan massa semakin kecil. Hal ini disebabkan semakin banyaknya kandungan nano abu sekam padi maka proses dekomposisi semakin besar, sehingga stabilitas termal semakin baik. Selanjutnya pada suhu 700$900^{\circ} \mathrm{C}$ semakin terjadi penurunan berat batu kapur. Pada suhu $900^{\circ} \mathrm{C}$ tidak terjadi lagi penurunan berat sampel batu kapur. hal ini menunjukan bahwa pada suhu $900^{\circ} \mathrm{C}$ telah terjadi kestabilan pembakaran batu kapur.

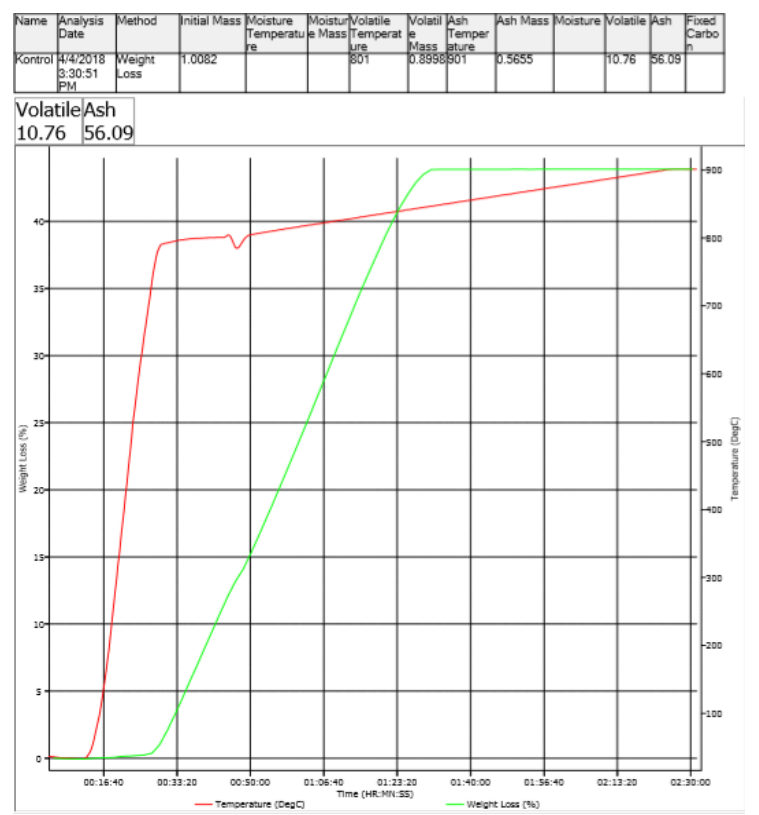

Gambar 2. Kurva TGA ( Thermal Gravimetry Analysis ) batu kapur

Analisis kristalisasi nano partikel menggunakan XRD (X-Ray Difraction), yang mana bertujuan untuk identifikasi fasa dan ukuran kristalnya. Dari hasil XRD, didapatkan diffraktogram sampel pada pengukuran $2 \Theta$. Puncak pada sampel batu kapur ditunjukan pada Gambar 3.

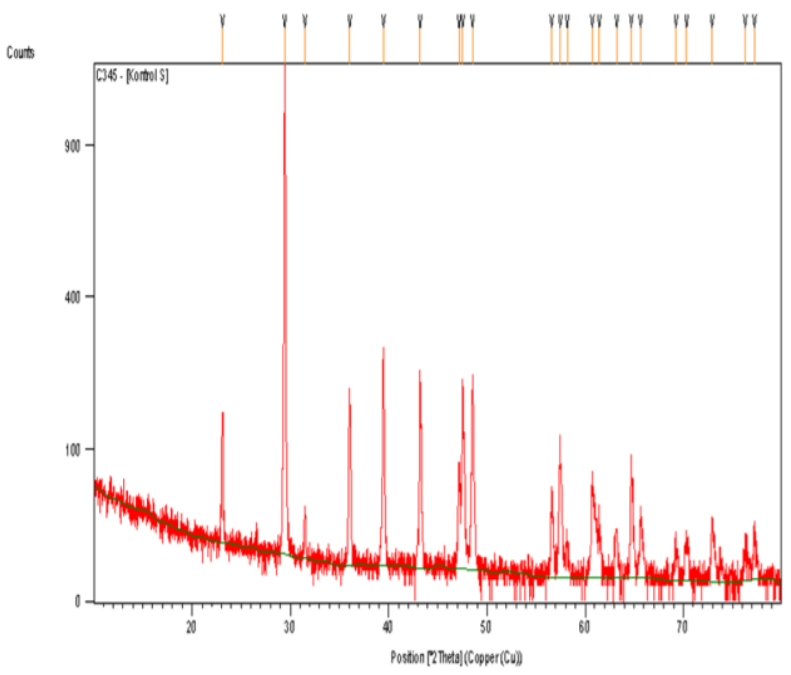

Gambar 3. Spektra XRD Kontrol batu kapur 
Pada sampel batu kapur didapatkan pada $2 \Theta=29,45$ yang merupakan karakteristik dari puncak Kristal $\mathrm{CaO}$. Puncak lain masih didapatkan dengan intensitas yang lebih rendah dari puncak $\mathrm{CaO}$ yang teridentifikasi sebagai puncak karakteristik dari Kristal $\mathrm{CaCO}_{3}$ yaitu pada $2 \mathrm{O}=$ 39,47 ( Nakatani, et al., 2009 ). Selain itu pada sampel juga ditemukan puncak sengan intensitas yang sangat rendah yaitu $2 \Theta=69,28$; puncak ini merupakan puncak dari karakteristik $\mathrm{Ca}(\mathrm{OH})_{2}$ (Ngamcharussrichai, et al., 2010).

Untuk menentukan ukuran nano Kristal, dilakukan perhitungan dengan menggunakan persamaan Scherrer yaitu :

$$
\mathrm{D}=\frac{\pi \lambda}{B \cos \theta}
$$

Dari rumus di atas diketahui k merupakan konstanta yang nilainya bervariasi, namun pada penelitian ini nilai $\mathrm{k}$ adalah 1,0 karena intensitas yang digunakan adalah $100 \%$. Sedangkan $\lambda$ adalah panjang gelombang sinar-X yang digunakan yaitu 1,5406 $\dot{\mathrm{A}}$, merupakan panjang gekombaang $\mathrm{Cu}$ sebagai sember sinar - X, $\Theta$ adalah sudut Bragg, dan B adalah FWHM (full width half maximum) yang dipilih. Harga FWHM berbanding terbalik dengan ukiran kristal, jika harga FWHM semakin kecil maka ukuran kristal akan semakin besar.

Berdasarkan persamaan Scherrer dapat diketahui ukuran kristal $\mathrm{CaO}$ yang terbentuk adalah : $51,39 \mathrm{~nm}$.

Untuk analisis morfologi mikro batu kapur Bukit Jimbaran digunakan SEM (Scanning Electron Microscopy) dan hasil yang diperoleh pada karakterisasi ini dapat dipaparkan pada Gambar 4.

Berdasarkan Gambar 4 menunjukkan morfologi permukaan batu kapur memiliki ukuran yang cukup besar, dengan bentuk tidak beraturan, kasar, dan padat. Menurut Saksono, et al. (2007), Kristal batu kapur mempunyai tiga bentuk kristal berbeda, yaitu : kalsit, aragonite, dan vaterit. Kalsit berupa kubus padat, vaterit berupa bentuk seperti bunga (flower-like), sedangkan aragonite berbentuk seperti kumpulan jarum. Berdasarkan bentuk kristal pada Gambar 2, maka dapat diketahui sampel batu kapur Bukit Jimbaran memiliki bentuk bunga (vaterit).

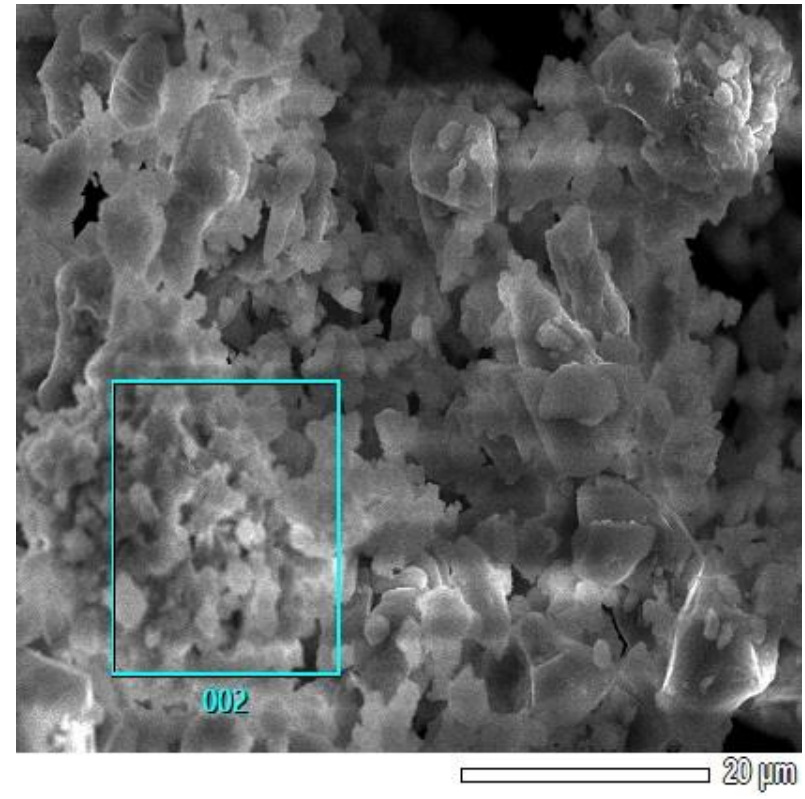

Gambar 4. Morfologi mikro batu kapur alam Bukit Jimbaran, Bali

Hasil analisis komposisi kimia batu kapur sebelum kalsinasi dapat dilihat pada Gambar 5.

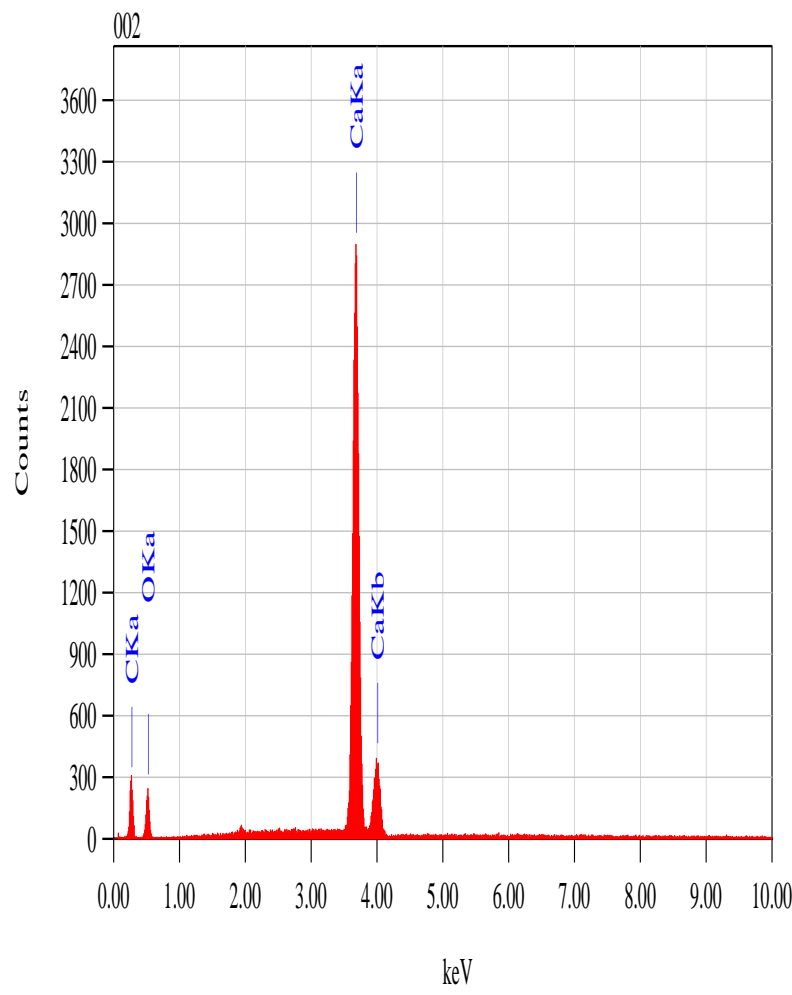

Gambar 5. Pola difraksi sinar X batu kapur Alam Bukit Jimbaran, Bali 


$\begin{array}{lll}\text { Element } & \begin{array}{r}(\mathrm{keV}) \\ \text { Atom\% }\end{array} & \begin{array}{l}\text { Mass\% } \\ \text { Cation }\end{array} \\ \text { C K } & 0.277 & 15.55 \\ 24.44 & & \\ \text { O K } & 0.525 & 50.45 \\ 59.54 & & \\ \text { Ca K } & 3.690 & 34.00 \\ \text { 16.02 } & & \\ \text { Total } & & \\ 100.00 & & \end{array}$

Berdasarkan Gambar 5 dapat diketahui komposisi kimia batu kapur mengandung unsur $\mathrm{C}$ : 15,55\% ; unsur O : $50,45 \%$ dan unsur $\mathrm{Ca}: 34,00 \%$. Pada sampel batu kapur terlihat masih tingginya kadar unsur $\mathrm{C}$, dan juga kandungan unsur $\mathrm{Ca}$ yang cukup rendah yaitu $34,00 \%$. Sedangkan untuk unsur $\mathrm{O}$ masih cukup tinggi yaitu sebesar 50,45\%, hal ini dikarenakan adanya senyawa $\mathrm{Ca}(\mathrm{OH})_{2}$ dan kadar air yang cukup tinggi pada sampel.

\section{SIMPULAN}

Berdasarkan penelitian yang telah dilakukan dapat disimpulkan bahwa batu kapur Bukit Jimbaran memiliki komposisi dominan pada gugus fungsi $\mathrm{O}-\mathrm{H}, \mathrm{C}-\mathrm{H}$, dan $\mathrm{C}-\mathrm{O}$, yang mana didalamnya banyak terdapat unsur $\mathrm{CaCO}_{3}$ dan $\mathrm{CaO}$, untuk ukuran kristal batu kapur setelah dihitung dengan persamaan Scherrer dari data yang diperoleh adalah 51,39 $\mathrm{nm}$. Sedangkan untuk morfologi mikro batu kapur Bukit Jimbaran memiliki bentuk yang tidak beraturan, kasar, dan padat, yang memiliki bentuk seperti bunga (vaterit), serta komposisi kimia batu kapur mengandung unsur $\mathrm{C}: 15,55 \%$; unsur $\mathrm{O}: 50,45 \%$ dan unsur $\mathrm{Ca}: 34,00 \%$.

\section{UCAPAN TERIMA KASIH}

Penulis mengucapkan terimakasih kepada seluruh staf Laboratorium Program Studi Kimia dan Laboratorium Penelitian Terpadu Fakultas Matematika dan Ilmu Pengetahuan Alam Universitas Udayana yang telah membantu dalam kelancaran penelitian ini, dan penulis juga megucapkan terimakasih kepada seluruh pihak yang membantu dalam penyelesaian penelitian ini.

\section{DAFTAR PUSTAKA}

Alba, A.C., Santamaria, J., Merida, J.M., Moreno, T.R., Martin, A.D., Jimenez, L.A., and Mairelez, T.P., 2010, Heterogeneous Transesterification Processes by Using $\mathrm{CaO}$ Supported on Zinc Oxsida as Basic Catalysts, Catalysts Today, 149 : 281-287

Albuquerque Monica CG., Jimenez-Urbistondo I., and Santamaria-Gonzalez Jose, 2008, CaO Supported on Mesoporous Silicas as Basic Catalysts of Transesterification Reaction, Appl Catal A : Gen, 334 : 35-43

Ferguson B.J. and Mabry R.L., 1997, Laboratory Diagnosis. Otolaryngol Head Neck Surg, $117: 12-26$

Granados, M.L., Poves, M.D.Z., Alonso, D.M., Mariscal, R., Galisteo, F.C., Moreno-Tost, R., Santamaria, J., and Fierro, J.L.G., 2007, Biodisel from Sunflower Oil by Using Activated Calcium Oxsida, Applied Catalysis B : Environmental, 73 : 317-326

Gusti, J., 2008,Pengaruh Penambahan Surfaktan Pada Sintesis Senyawa Kalsium Fosfat Melalui Metode Pengendapan, Universitas Andalas, Padang

Liu X., He H., Wang Y., Zhu S., and Oiao X., 2008, Transesterifacation of Soybean Oil to Biodiesel Using $\mathrm{CaO}$ as a Solid Base Catalyst, Fuel, 87 : 216-221

Lukman, M., Yudyanto, dan Hartatiek, 2012, Sintesis Biomaterial Komposit $\mathrm{CaO}-\mathrm{SiO}_{2}$ Berbasis Material Alam (Batuan Kapur Dan Pasir Kuarsa) Dengan Variasi Suhu Pemanasan Dan Pengaruhnya Terhadap Porositas, Kekerasan, dan Mikrostruktur, Journal Sains, 2 (1) :

Ngamcharussrichai, Chawalit, Nuntashanti, Pramwit, Tanachai, Sithikorn, Bunyakiat, Kunchana, 2010, Biodiesel Production Through Transesterification Over Natural Calciums, Fuel Processing Tecnology 91 : 14091515

Noviyanti, Jasruddin, dan Eko, H.S., 2015, Karakterisasi Kalsium karbonat $\left(\mathrm{CaCO}_{3}\right)$ Dari Batu Kapur Kelurahan Tellu Limpoe 
Kecamatan Suppa, Sains dan Pendidikan Fisika, 1 (2) : 169-172

Saksono, N., Mubarok, M.H., Widaningroem, R., dan Bismo S., 2007, Pengaruh Medan Magnet Terhadap Konduktivitas Lartan $\mathrm{Na}_{2} \mathrm{CO}_{3}$ dan $\mathrm{CaCl}_{2}$ serta presipitasi dan Marfologi Partikel $\mathrm{CaCO}_{3}$ Pada Sistem Fluida Statis, Jurnal Teknologi, 4: 317323
Sucipto, E., 2007, Hubungan PemaparanxPertikel Debu Pada Pengolahan Batu Kapur Terhadap Penurunan Kapasitas Fungsi Paru, Universitas Diponegoro, Semarang

Tang Y, Meng Mei, Zhang Jie, and Lu yong, 2011, Efficient Preparation of Biodiesel From Rapeseed Oil Over Modified CaO, Applied Energy, 88:2735-2739 